\title{
Associations between adult attachment dimensions and attitudes toward pain behaviour
}

\author{
Lachlan A McWilliams PhD, Paul DJ Murphy MSc, S Jeffrey Bailey MSc
}

LA McWilliams, PDJ Murphy, SJ Bailey. Associations between adult attachment dimensions and attitudes toward pain behaviour. Pain Res Manage 2010;15(6):378-384.

BACKGROUND: Despite the important role positive reinforcement of pain behaviour is believed to play in chronic pain, there is a paucity of research regarding factors that influence the provision of such reinforcement. Attachment theory suggests that individuals high in attachment avoidance view the pain behaviour of others in a negative manner and would, therefore, provide little reinforcement of pain behaviour. As an initial step in evaluating this model, relationships between attachment dimensions and attitudes toward pain behaviour were examined. Attachment avoidance was hypothesized to be negatively associated with accepting attitudes toward pain behaviour.

METHODS: A sample of undergraduate students $(n=160)$ completed the Relationships Structures Questionnaire, which provides global ratings of adult attachment dimensions (anxiety and avoidance) by assessing attachment across four relationship targets (friend, mother, father and romantic partner). Attitudes regarding the acceptability of pain behaviour were assessed using male and female versions of the Appropriate Pain Behaviour Questionnaire (APBQ).

RESULTS: Consistent with the hypothesis, attachment avoidance was negatively correlated with both APBQ-Female and APBQ-Male scores. Multiple regression analyses were used to investigate the relationships between the attachment scales and the APBQ scales while statistically adjusting for sex and testing for interaction effects. The findings revealed complex relationships involving interaction effects that provided further support for the hypothesis.

CONCLUSIONS: The findings provided support for the hypothesis that attachment avoidance is associated with less accepting attitudes toward pain behaviour. Additional research regarding the role of attachment and attitudes on responses to pain behaviour is warranted.

Key Words: Attachment; Pain behaviour; Social communication model

\section{Les associations entre les dimensions d'attachement des adultes et les attitudes envers les comportements vis-à-vis de la douleur}

HISTORIQUE : Malgré le rôle important attribué au renforcement positif du comportement vis-à-vis de la douleur en cas de douleur chronique, il existe peu de recherche sur les facteurs qui influent sur la prestation d'un tel renforcement. D'après la théorie de l'attachement, les personnes qui évitent beaucoup l'attachement perçoivent le comportement de douleur des autres de manière négative et fourniraient donc peu de renforcement du comportement vis-à-vis de la douleur. Comme première étape d'évaluation de ce modèle, les chercheurs ont examiné les relations entre les dimensions de l'attachement et les attitudes envers les comportements de douleur. Ils ont postulé que l'évitement de l'attachement nuisait aux attitudes d'acceptation envers les comportements de douleur. MÉTHODOLOGIE : Un échantillon d'élèves du premier cycle $(n=160)$ a rempli le questionnaire sur les structures relationnelles, qui fournit des évaluations globales des dimensions d'attachement des adultes (anxiété et évitement) en mesurant l'attachement dans quatre cibles relationnelles (ami, mère, père et partenaire romantique). Ils ont divisé les attitudes relatives à l'acceptabilité du comportement de douleur au moyen des versions pour hommes et pour femmes du questionnaire APBQ sur le comportement de douleur convenable.

RÉSULTATS : Conformément à l'hypothèse, l'évitement de l'attachement était corrélé négativement avec les indices d'APBQ des femmes et des hommes. Les chercheurs ont utilisé les analyses de régression multiple pour explorer les liens entre les échelles d'attachement et les échelles d'APBQ tout en effectuant les rajustements statistiques selon le sexe et en testant les effets d'interaction. Les résultats ont révélé les relations complexes des effets d'interaction qui corroborent encore davantage l'hypothèse.

CONCLUSIONS : Les résultats étayent l'hypothèse selon laquelle l'évitement de l'attachement s'associe à des attitudes de moins grande acceptation des comportements de douleur. Des recherches supplémentaires s'imposent au sujet du rôle de l'attachement et des attitudes envers les réponses aux comportements de douleur.

However, several studies have failed to support it $(5,6)$. More recently, Cano and Williams (7) introduced an alternative model suggesting that some verbal pain behaviours may serve as opportunities to build intimacy with one's partner and that empathic and validating responses to such behaviours may have positive outcomes such as enhanced emotion regulation.

Despite the important roles that responses to pain behaviour are believed to play, there is a paucity of research regarding factors that may influence the provision of solicitous responses to pain. However, the social communication model of pain advanced by Craig (8) has drawn attention to social processes that could influence responses to individuals displaying pain behaviour. This model suggests that evaluations regarding pain can be influenced by characteristics of both individuals experiencing pain, referred to as senders, and by characteristics of patients and their partners (4) have supported Fordyce's model. 
observers. Past research has identified several sender variables that appear to influence observers' evaluations. For example, female sex, physical attractiveness (9) and pain expressiveness (10) have all been found to be positively associated with observers' pain ratings. Although observer variables have received far less attention, Hadjistavropoulos and Craig (11) posited that inferences regarding pain would be influenced by the observers' perceptual and social sensitivities.

Sullivan et al $(12,13)$ provided one of the only lines of research to consider an individual difference variable in relation to perceptions of others' pain. In these two studies, university student participants completed the Pain Catastrophizing Scale (PCS) (14) and observed a series of video clips of students undergoing a cold pressor task. Participants were then asked to estimate the intensity of pain experienced by those in the video clips. The first of these studies (12) found participants' PCS scores to be associated with higher ratings of others' pain and with the tendency to rely on pain behaviour when making inferences about others' pain. Relative to those with low PCS scores, those with high PCS scores inferred pain ratings that more closely corresponded to the pain ratings made by those undergoing the cold pressor task. However, it is important to note that the overall findings indicated that this seemingly superior accuracy occurred because pain catastrophizers were less likely than noncatastrophizers to underestimate pain levels. There was no evidence that those high in catastrophizing were more sensitive to changes in pain within individuals. The second study (13) also found PCS scores to be positively associated with inferred pain ratings; however, in this case, discrepancies between the inferred pain ratings and the actual self-report ratings were unrelated to PCS scores. Viewed within the social communication model, catastrophizing can be considered an individual difference variable that is related to observers' interpretations of pain behaviour (ie, relatively high ratings of the pain of others). Sullivan et al (12) suggested that catastrophizing may also influence caregiving responses to those experiencing pain, but this possibility has not yet been investigated.

Bowlby's (15) attachment theory has been a major influence in social and developmental research. It also provides a promising framework for understanding individual differences relevant to the social communication model of chronic pain. In brief, attachment theory suggests that children develop internal working models of self and others based on early interactions with caregivers. Once these models develop, they continue into adulthood and guide behaviour with others.

Adult attachment research has evolved along two separate lines (16). Developmental researchers have used the Adult Attachment Interview to infer states of mind regarding childhood experiences with caregivers. The second approach developed within social and personality research and is used in the current study. Within this approach, attachment was initially conceptualized in a categorical manner, and selfreport measures of attachment-related thoughts and feelings in adult relationships were used to characterize individuals in terms of three or four specific attachment styles. Bartholomew and Horowitz's (17) model, which posits that adult attachment involves two orthogonally related dimensions, is now the most commonly used approach and has received more support than earlier categorical approaches $(18,19)$. In this model, model of self (also labelled anxiety) refers to the attachment dimension that can range from an internalized sense of self-worth to anxiety regarding rejection based on beliefs of personal unworthiness. Model of others (also labelled avoidance) refers to a dimension ranging from trust and comfort with intimacy to mistrust and avoidance of close relationships.

It is important to note that anxiety and avoidance are also conceptualized as underlying the attachment styles identified in earlier research. Each dimension can be dichotomized as positive or negative, yielding four possible combinations that correspond to the attachment styles included in Bartholomew and Horowitz's model (17). These styles include secure (low anxiety and low avoidance), preoccupied (high anxiety and low avoidance), fearful (high anxiety and high avoidance) and dismissing (low anxiety and high avoidance) attachment. It has been argued that these categories have 'emergent properties' that would be missed unless combinations of the dimensions are considered (20). To investigate this possibility, it is now common practice to test for anxiety by avoidance interaction effects. While this approach is often used, significant interaction effects are rarely found.

There is a large body of research applying attachment theory to responses to the emotions of others. Of particular relevance to the social communication model, adult attachment has been found to be related to a wide range of variables reflecting interpersonal sensitivity and responsiveness. In general, these studies have found anxiety to be associated with poorer accuracy in detecting emotions (21), a tendency to provide negative explanations for the behaviour of romantic partners $(22)$, and compulsive and intrusive caregiving $(23,24)$. Attachment avoidance has been found to be positively associated with negative explanations for the behaviour of romantic partners (22) and negatively associated with supportiveness during laboratory stressors $(24,25)$.

There is a growing body of research examining the role of attachment in the experience of pain (26). For example, selfreports of anxious attachment have been found to be positively associated with self-reports of catastrophizing, fear of pain and hypervigilance to pain (27), and with a catastrophizing response to cold pressor-induced pain (28). Attachment theory has not been directly applied as a framework for investigating responses to the pain of others. However, the research noted above is suggestive of a model in which those with insecure attachment view the pain behaviour of others in a negative manner and, consequently, do not reinforce pain behaviour. As an initial step in evaluating this model, relationships between adult attachment dimensions and attitudes regarding the acceptability of pain behaviour were examined. Given that attachment avoidance reflects one's views of others, and recent theoretical work (29) indicating that those high in avoidance react to others' distress with disdain, it was hypothesized that attachment avoidance would be negatively associated with accepting attitudes toward pain behaviour. While attachment anxiety could also be expected to be related to unhelpful responses to others in pain (eg, intrusive caregiving), previous research was not suggestive of a hypothesis regarding the relationship between anxiety and attitudes toward pain behaviour. Given the evidence and theoretical suggestions indicating that relationships between attachment dimensions and dependent 
TABLE 1

Descriptive statistics and correlations between the Relationships Structures Questionnaire (RSQ) and the two Appropriate Pain Behaviour Questionnaire (APBQ) scales $(n=160)$

\begin{tabular}{lccccccc}
\hline & & & \multicolumn{6}{c}{ Correlations } \\
\cline { 4 - 8 } Scales & $\alpha$ & Mean \pm SD & $\mathbf{1}$ & $\mathbf{2}$ & $\mathbf{3}$ & $\mathbf{4}$ & $\mathbf{5}$ \\
\hline $\begin{array}{l}\text { 1. RSQ global } \\
\quad \text { anxiety }\end{array}$ & 0.86 & $1.77 \pm 0.78$ & - & & & & \\
$\begin{array}{l}\text { 2. RSQ global } \\
\quad\end{array}$ & 0.88 & $2.53 \pm 0.83$ & $0.51^{\ddagger}$ & - & & & \\
$\quad \begin{array}{l}\text { avoidance } \\
\text { 3. APBQ-Male }\end{array}$ & 0.88 & $77.63 \pm 13.57$ & -0.07 & $-0.24^{\dagger}$ & - & & \\
$\begin{array}{l}\text { 4. APBQ-Female } \\
\text { APB }\end{array}$ & 0.81 & $82.88 \pm 10.20$ & -0.08 & -0.18 & $0.66^{\ddagger}$ & - & \\
5. Sex & - & - & -0.07 & $-0.19^{\star}$ & $0.48^{*}$ & $0.23^{\dagger}$ & - \\
\hline
\end{tabular}

${ }^{*} P \leq 0.05 ;{ }^{\dagger} P \leq 0.01 ;{ }^{\ddagger} P \leq 0.001$ (two-tailed tests); ${ }^{\S}$ Male $=0$ and female $=1$

variables may be moderated by the other attachment dimension (20), interaction effects were also tested.

\section{Participants and procedure}

\section{METHODS}

Undergraduate students from Acadia University (Wolfville, Nova Scotia) were recruited via e-mail to participate in a survey regarding relationship style and friendship interaction. One hundred sixty-five participants attended data collection sessions. Of these, 64 men and 96 women, ranging from 18 to 50 years of age (mean $[ \pm S D] 20.68 \pm 3.37$ years), completed the entire survey. The sample was primarily single $(93.8 \%)$ and Caucasian (81.9\%).

During recruitment, interested participants contacted the researcher and were scheduled to attend one of several data collection sessions. Data collection occurred in groups of one to six participants and took place in a classroom at Acadia University. Potential participants were asked to bring their universityissued personal laptop computers to complete the survey online. When they arrived at the collection session, participants were asked to sign a consent form indicating that they understood the voluntary and confidential nature of the study, and that they approved the use of the data they provided. Participants were then asked to complete an online questionnaire package and were directed to a website (www.surveymonkey.com) containing all of the testing materials. On completion, participants were given a debriefing handout that outlined the study in greater detail and provided contact information for the researchers. Participants were compensated with either course credit if they were registered in Introductory Psychology, or with $\$ 10$. The present study was approved by Acadia University's research ethics board.

\section{Measures}

Demographics questionnaire: A brief questionnaire was used to obtain demographic information including age, sex, marital status and ethnic/racial background.

Relationships Structures Questionnaire (21): The Relationships Structures Questionnaire (RSQ) is a shortened version of the Experiences in Close Relationships questionnaire (30) designed to assess attachment patterns in a variety of close relationships. It uses 10 self-report items to assess attachment avoidance and anxiety with respect to each of four targets (ie, best friend, mother, father and romantic partner).
Respondents are asked to indicate their level of agreement with each of the 40 items using a response scale ranging from 1 (strongly disagree) to 7 (agree strongly). Target-specific anxiety and avoidance scales are created by averaging responses to the relevant items (four anxiety items and six avoidance items) from each relationship target. Global anxiety and avoidance scores can be created by averaging responses to the 16 anxiety and 24 avoidance items. Higher scores on these scales indicate higher levels of attachment insecurity. Given that there were no hypotheses regarding specific attachment targets, Fraley et al's (21) strategy of using these global scales was followed.

Appropriate Pain Behaviour Questionnaire (31): The Appropriate Pain Behaviour Questionnaire (APBQ) is a 14-item self-report measure designed to assess individual beliefs regarding appropriate or acceptable public pain responses. There are two versions of the scale, APBQ-Male and APBQFemale. The questionnaires ask participants to rate their agreement using a seven-point Likert scale ranging from 1 (strongly disagree) to 7 (strongly agree). Examples of items on the male questionnaire include the following: "It is acceptable for men to cry when in pain", "I feel sympathy toward men who are displaying pain" and "It is all right for men to groan when in pain". Other than the use of different sex terms, items in the male and female versions of the questionnaire are identical. Six items are reverse coded, and responses are summed to obtain a total score. High scores represent an agreement that overt pain responses are appropriate. Nayak et al (31) reported reliability coefficient alphas of 0.89 and 0.85 for the APBQMale and APBQ-Female, respectively, in a sample of American undergraduate students, and 0.80 and 0.74 , respectively, in a sample of undergraduate students from India.

\section{RESULTS}

Descriptive statistics and internal consistency coefficients for the self-report measures are presented in Table 1. Each measure had a high level of internal consistency. Correlations between the self-report measures, and between the self-report measures and sex are also reported in Table 1. Consistent with the hypothesis, avoidance was negatively correlated with APBQMale and APBQ-Female scores, whereas anxiety was unrelated to these measures.

Aside from the correlations directly relevant to the study hypothesis, two other findings presented in Table 1 should be noted. First, there was a large significant positive association between the attachment scales. This large association raises the possibility that multicollinearity could be a problem in the subsequent multiple regression analyses. Second, sex (male $=0$, female $=1$ ) was positively associated with both APBQ-Male and APBQ-Female scores, and was also negatively associated with avoidance. Thus, sex could be a confounder in the relationships between avoidance and the APBQ scales, and should be adjusted for in the multiple regression analyses.

Two hierarchical multiple regression analyses were used to investigate whether the attachment variables could contribute unique variance to the prediction of APBQ scores beyond that contributed by sex, and to test for interaction effects. Interactions were tested following Aiken and West's (32) recommendations. The anxiety and avoidance scales were centred (ie, put in deviation score form with means of zero) and interaction terms (variables created by multiplying the relevant 
TABLE 2

Standardized beta values and summary statistics from linear regression models predicting Appropriate Pain Behaviour Questionnaire-Male scores with Relationships Structures Questionnaire global attachment scales ( $n=160)$

\begin{tabular}{lccc}
\hline Independent variables & Beta coefficient & $\mathbf{R}^{\mathbf{2}}$ & $\Delta \mathbf{R}^{\mathbf{2}}$ \\
\hline Step 1 & & $0.25^{\dagger}$ & \\
Sex & & & \\
Anxiety & -0.03 & & \\
Avoidance & -0.15 & & \\
Step 2 & & 0.27 & 0.02 \\
Sex & $0.46^{\dagger}$ & & \\
Anxiety & 0.10 & & \\
Avoidance & $-0.31^{\star}$ & & \\
Anxiety $\times$ avoidance & -0.12 & & \\
Anxiety $\times$ sex & -0.01 & & \\
Avoidance $\times$ sex & 0.21 & & \\
Step 3 & & 0.27 & \\
Sex & $0.44^{\dagger}$ & & \\
Anxiety & 0.15 & & \\
Avoidance & $-0.33^{\star}$ & & \\
Anxiety $\times$ avoidance & -0.20 & \\
Anxiety $\times$ sex & -0.14 & \\
Avoidance $\times$ sex & 0.23 & \\
Avoidance $\times$ anxiety $\times$ sex & 0.01 & \\
\hline
\end{tabular}

${ }^{*} P<0.05 ;{ }^{\dagger} P<0.001$ (two-tailed tests); ${ }^{\ddagger}$ Male $=0$, female $=1$

variables) were formed using the centred versions of the attachment scales. Interactions between the attachment dimensions and sex were also considered. In each regression model, sex and the attachment dimensions were entered in step 1, followed by the two-way interactions (anxiety by sex, avoidance by sex and anxiety by avoidance) in step 2, and the three-way interaction (anxiety by avoidance by sex) in step 3 . The variance inflation factor (VIF) statistic was used to quantify the severity of multicollinearity. A VIF value greater than 10 was used as a criterion for excessive multicollinearity (33). In both the multiple regression analyses reported below, no VIF values exceeded this criterion.

The regression model predicting APBQ-Male scores is presented in Table 2 . The variables entered in step 1 accounted for statistically significant variance in the APBQ-Male scores. In this stage of the analysis, sex was the only significant predictor variable, but avoidance had a marginally significant $(\mathrm{P}=0.08)$ negative association with APBQ-Male scores. The change in the $\mathrm{R}^{2}$ statistic indicated that the addition of the variables in step 2 did not significantly improve the model. However, after including the two-way interaction terms, the negative association between avoidance and APBQ-Male scores became statistically significant. The addition of the interaction terms can be conceptualized as a method of reducing statistical noise and providing a more powerful test of the relationship between avoidance and APBQ-Male scores. The addition of the threeway interaction term in step 3 did not significantly improve the model and did not alter the pattern of findings obtained in step 2 .

The regression model predicting APBQ-Female scores is presented in Table 3 . The variables entered in step 1 accounted for statistically significant variance in the APBQ-Female scores, with sex being the only significant predictor variable.
TABLE 3

Standardized beta values and summary statistics from linear regression models predicting Appropriate Pain Behaviour Questionnaire-Female scores with Relationships Structures Questionnaire global attachment scales $(n=160)$

\begin{tabular}{|c|c|c|c|}
\hline Independent variables & Beta coefficient & $\mathbf{R}^{2}$ & $\Delta \mathbf{R}^{2}$ \\
\hline Step 1 & & $0.07^{\dagger}$ & \\
\hline Sex $^{\ddagger}$ & $0.21^{*}$ & & \\
\hline Anxiety & -0.03 & & \\
\hline Avoidance & -0.12 & & \\
\hline Step 2 & & $0.09 *$ & 0.02 \\
\hline Sex & $0.21^{\dagger}$ & & \\
\hline Anxiety & -0.12 & & \\
\hline Avoidance & -0.22 & & \\
\hline Anxiety $\times$ avoidance & -0.01 & & \\
\hline Anxiety $\times$ sex & -0.16 & & \\
\hline Avoidance $\times$ sex & 0.01 & & \\
\hline Step 3 & & $0.11^{\dagger}$ & $0.02^{*}$ \\
\hline Sex & 0.11 & & \\
\hline Anxiety & 0.12 & & \\
\hline Avoidance & $-0.34^{*}$ & & \\
\hline Anxiety $\times$ avoidance & $-0.51^{*}$ & & \\
\hline Anxiety $\times$ sex & -0.08 & & \\
\hline Avoidance $\times$ sex & 0.19 & & \\
\hline Avoidance $\times$ anxiety $\times$ sex & $0.47^{\star}$ & & \\
\hline
\end{tabular}

${ }^{*} P<0.05 ;{ }^{\dagger} P<0.01$ (two-tailed tests); ${ }^{\ddagger}$ Male $=0$, female $=1$

The addition of step 2 did not significantly improve the model, but it was improved by the inclusion of the three-way interaction term in step 3. The final model included three statistically significant predictor variables, including the three-way interaction term. To interpret this three-way interaction, the regression equation from the final model was used to calculate APBQ-Female values (ie, plot points) for high and low values (ie, one SD above and below the mean) of anxiety and avoidance across both sexes. These points can be used to illustrate the interaction effect.

Figure 1 illustrates the relationship between avoidance, as a function of anxiety, and APBQ-Female scores among men. In this case, the lines representing those low and high in anxiety are close together and are almost parallel to each other. This pattern suggests that there is no substantial association between anxiety and APBQ-Female scores among men. The two lines representing low and high anxiety are also negatively sloped. This pattern indicates that among men, APBQ-Female scores are negatively associated with avoidance and that this relationship occurs at both low and high levels of anxiety. To further explore these findings, Bartholomew and Horowitz's (17) attachment style labels were applied to the points used to illustrate the interactions. Using this conceptual framework, men with secure (low anxiety and low avoidance) and preoccupied (high anxiety and low avoidance) attachment appear to have more accepting attitudes toward the pain behaviour of women than those with fearful (high anxiety and high avoidance) and dismissing (low anxiety and high avoidance) attachment. However, such differences were not formally tested.

Figure 2 illustrates the relationship between avoidance, as a function of anxiety, and APBQ-Female scores among women. In this case, the relationship between avoidance and APBQFemale scores was moderated by anxiety. Among women with low anxiety, there was no association between avoidance and 


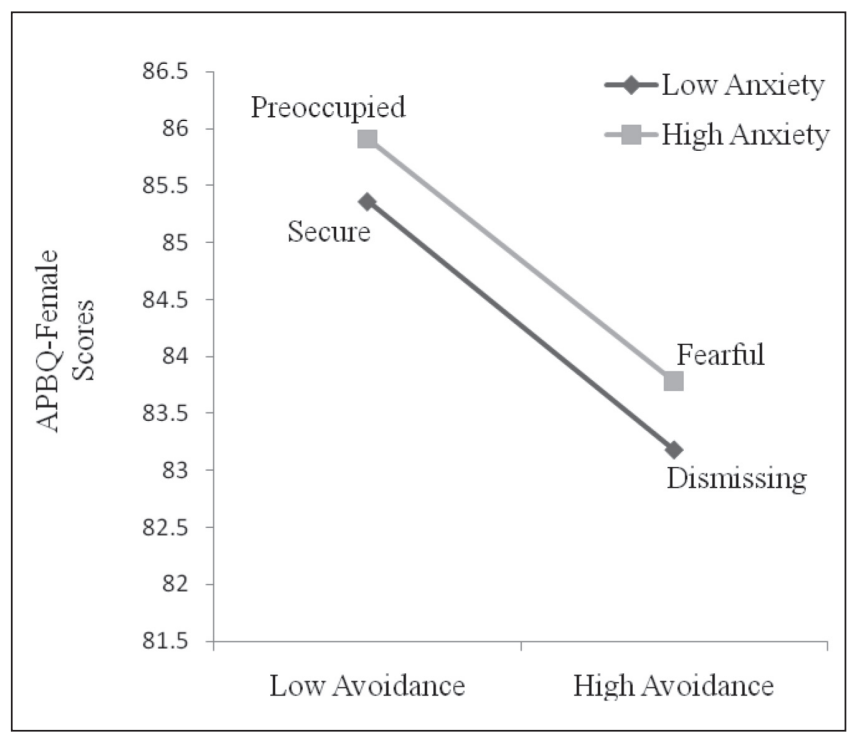

Figure 1) Graph illustrating relationships between Relationships Structures Questionnaire scales (global anxiety and avoidance) and Appropriate Pain Behaviour Questionnaire (APBQ)-Female scores among men

APBQ-Female scores (ie, the line representing those low in anxiety had only a slight positive slope). In contrast, among women with high anxiety, there was a negative association between avoidance and APBQ-Female scores (ie, the line representing those high in anxiety was negatively sloped). When Bartholomew and Horowitz's (17) attachment style categories are considered, those with preoccupied (high anxiety and low avoidance) attachment have the highest APBQFemale scores and those with fearful (high anxiety and high avoidance) attachment have the lowest scores. The secure (low anxiety and low avoidance) and dismissing (low anxiety and high avoidance) styles both fell approximately midway between the fearful and preoccupied group. Again, these differences were not formally tested.

\section{DISCUSSION}

Fordyce's (2) behavioural model of chronic pain led to research and clinical attention to the role that significant others' responses to pain behaviour may play in chronic pain. Little effort has been directed toward understanding the factors that influence such responses to pain behaviour. Craig's social communication model (8) has drawn attention to social processes that could influence responses to individuals displaying pain including characteristics both of the individual experiencing pain and the individual observing those in pain. Attachment theory is suggestive of a model in which individuals with avoidant attachment view the pain behaviour of others in a negative manner and, consequently, do not reinforce pain behaviour. As an initial step in evaluating this model, relationships between attachment dimensions and attitudes regarding the acceptability of pain behaviour were examined.

Avoidance had significant negative correlations with the APBQ scales, and anxiety was not significantly correlated with the APBQ scales. Thus, the initial correlation analyses were supportive of the hypothesis that those with avoidant attachment view the pain behaviour of others as unacceptable. There

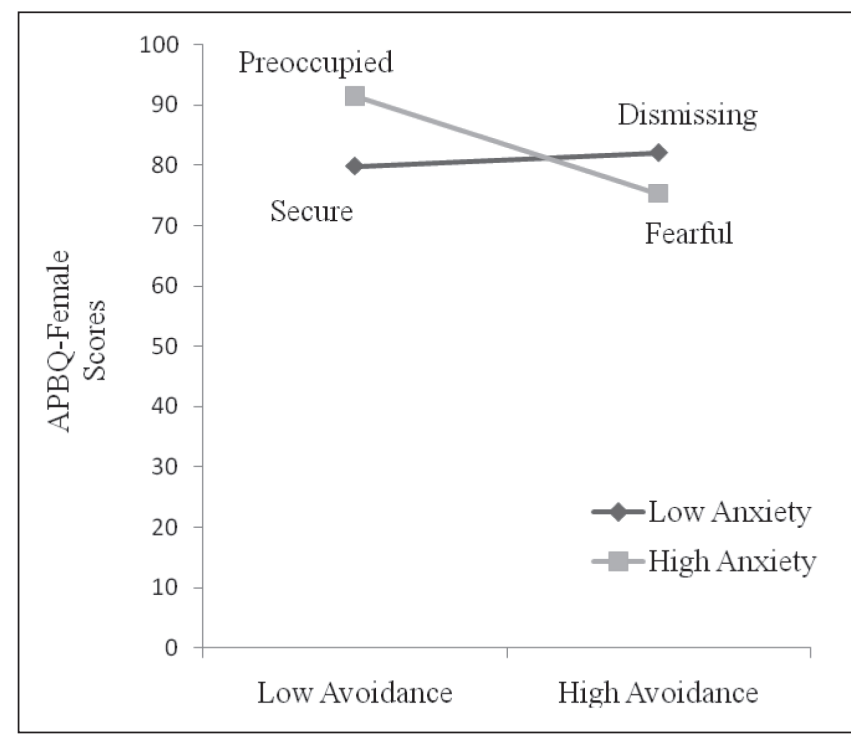

Figure 2) Graph illustrating the Relationships Structures Questionnaire global anxiety scale moderating the relationship between the Relationships Structures Questionnaire global avoidance scale and Appropriate Pain Behaviour Questionnaire (APBQ)Female scores among women

were two other initial findings of note. First, sex had significant positive associations with the APBQ scales. This finding indicates that women reported being more accepting of the pain behaviour of men and women, and is consistent with past research $(31,34)$. Second, the correlation between anxiety and avoidance was large, with the $\mathrm{R}^{2}$ value indicating $26 \%$ shared variance. This finding is somewhat surprising because Bartholomew and Horowitz (17) posited that the two attachment dimensions have an orthogonal relationship. However, this finding is consistent with previous studies that have found attachment dimensions to be associated when parental attachment $(35)$ and romantic attachment $(35,36)$ were considered.

Multiple regression analyses were used to determine whether the attachment variables contributed unique variance to the prediction of APBQ scores beyond that contributed by sex, and to examine whether the combination of the attachment dimensions had emergent properties that could not be observed when considering the attachment dimensions independently. The regression analyses were also supportive of the study hypothesis, but revealed a more complex pattern of relationships between avoidance and attitudes toward pain behaviour. In the case of the APBQ-Male scale, a significant negative association with avoidance was found, but this relationship was only revealed after statistically adjusting for two-way interactions involving sex and the attachment dimensions. In the case of the APBQFemale scale, the three-way interaction effect was significant.

To illustrate the interaction effect regarding APBQ-Female scores, the final regression equation was used to calculate predicted APBQ-Female scores for specific attachment dimension combinations across both sexes. These values were plotted to illustrate the interaction effect. Figure 1 illustrates the absence of an interaction between the two attachment dimensions among men. Consistent with the hypothesis of the study, this figure also indicates a negative association between avoidance and APBQ-Female scores. The pattern among women was 
more complicated, and involved an interaction between anxiety and avoidance (Figure 2). Among women low in anxiety, there was no association between avoidance and APBQFemale scores. Among women high in anxiety, avoidance was negatively associated with APBQ-Female scores.

Because the points used in the figures illustrating the interaction effect all correspond to a specific attachment style in Bartholomew and Horowitz's (17) model, these attachment labels were applied to the points in these figures. The figure illustrating the anxiety by avoidance interaction among men indicates that those characterized as preoccupied (ie, high anxiety and low avoidance) were the most accepting of the pain behaviour of women, and that those characterized as dismissing (ie, low anxiety and high avoidance) were least accepting. While the difference between these two styles was not tested with an inferential statistic, it is important to note that this finding is consistent with past research (17) demonstrating strong differences between these groups in terms of interpersonal variables such as level of intimacy and caregiving. Among women, those characterized as preoccupied (ie, high anxiety and low avoidance) had the highest levels of acceptance regarding the pain behaviour of women, whereas those characterized as fearful (high anxiety and high avoidance) had the least accepting attitudes.

Among both men and women, the consistent finding regarding the attachment styles and APBQ-Female scores was that those with preoccupied attachment reported the greatest level of acceptance of female pain behaviour. Those with preoccupied attachment attempt to gain the acceptance of valued others as a means of achieving a sense of self-acceptance (17). Those with preoccupied attachment may be particularly accepting of the pain behaviour of others as part of a broader strategy of winning the approval of others by being accepting of them. Because dismissing attachment is characterized by interpersonal coldness and a relative absence of engagement with others (37), those with dismissing attachment would be expected to report the lowest level of acceptance of pain behaviour. This expectation was met when men's attitudes toward the pain behaviour of women were considered. However, as illustrated in Figure 2, women with dismissing attachment were not particularly nonaccepting of the pain behaviour of other women (ie, their APBQ-Female scores were similar to those with secure attachment). Dismissing attachment is believed to involve defensive denial of the value of close relationships (16). One potential explanation for the unexpected finding among women is that women with dismissing attachment may not be particularly compelled to maintain a defensive orientation to other women. However, in the absence of research regarding attachment and same-sex friendships, this explanation should be considered speculative.

It is important to note that the associations found in the present study indicate that attachment does not account for a large portion of variance in APBQ scores. However, these modest findings are likely more reflective of the methodology than of the actual impact of attachment on evaluating the pain behaviour of others. While the measure of attitudes toward pain behaviour used is psychometrically sound, it is also very limited. It does not take into account other factors that could influence ratings of acceptability such as the individual displaying pain behaviour (ie, a specific person or attachment figure), the context of the behaviour (eg, the pain behaviour history of the individual in pain) or the type of pain associated with the pain behaviour (eg, severe pain resulting from an injury versus mild pain from a minor health condition). Accounting for such variables would be expected to result in stronger associations. For example, one's attachment may play a very small role in assessing the acceptability of pain behaviour in response to severe acute pain, but may play a very large role in assessing the acceptability of persistent pain behaviour associated with minor injury.

Attitudes regarding the acceptability of pain behaviour may have important consequences in terms of shaping the behaviour of others. Research regarding behavioural approaches to chronic pain has focused on responses to pain behaviour believed to serve as positive reinforcement (eg, solicitousness) or on those that may serve as positive punishment (eg, anger and hostility). The present study is based on the idea that those high in avoidance view the pain behaviour of others in a more negative manner and are, therefore, less likely to provide solicitous responses and more likely to provide punishing responses. The present findings provide support for the first step in this model (ie, negative appraisal of the pain behaviour), but additional research is required to determine whether attachment variables actually influence behavioural responses to the pain behaviour of others. If those high in avoidance do provide pain-related support that does not encourage pain behaviour, having a significant other high in attachment avoidance may decrease one's risk of developing chronic pain. However, it is also important to consider the possibility of other forms of pain-related support that could be more adaptive than solicitous and punishing responses. Such forms of support could include intimacy-building empathic responses to pain communications (7) or encouragement to remain active (38). Past research indicates that securely attached individuals (ie, those with low anxiety and avoidance) are more likely to provide effective social support (25); consequently, those with secure attachment may reduce the risk of their spouse developing chronic pain by responding to pain behaviour in a manner that is adaptive and by providing emotional support that could serve as a coping resource (39).

Hadjistavropoulos and Craig (10) raised the possibility that evaluations of pain are influenced by the characteristics of the individual observing the pain. Aside from research by Sullivan et al $(12,13)$ regarding pain catastrophizing, and an earlier study (40) regarding unsupportive attributional styles, there has been no research addressing the influence of individual difference variables in judgements and responses related to the observation of others' pain. The present findings indicate that attachment avoidance is associated with beliefs regarding the acceptability of pain. Further research regarding the role of attachment in caregiving responses to pain behaviour could potentially expand behavioural conceptualizations of chronic pain by identifying interpersonal variables that influence the reinforcement or punishment of pain behaviour. Attachment theory could also be used as a framework for studying intimacy in the context of chronic pain.

ACKNOWLEDGEMENTS: This research was supported by the Acadia University Research Fund and a Standard Operating Grant awarded to Dr McWilliams from the Social Sciences and Humanities Research Council of Canada. 


\section{REFERENCES}

1. Gil KM, Keefe FJ, Crisson JE, Van Dalfsen PJ. Social support and pain behavior. Pain 1987;29:209-17.

2. Fordyce WE. Behavioral Methods for Chronic Pain and Illness. St Louis: Mosby, 1976.

3. Flor H, Kerns RD, Turk DC. The role of the spouse in the maintenance of chronic pain. J Psychosom Res 1987;31:251-60.

4. Romano JM, Turner JA, Friedman LS, et al. Sequential analysis of chronic pain behaviors and spouse responses. J Consult Clin Psychol 1992;60:777-82.

5. Lousberg R, Schmidt AJ, Groenman NH. The relationship between spouse solicitousness and pain behavior: Searching for more experimental evidence. Pain 1992;51:75-9.

6. Schwartz L, Slater MA, Birchler GR. The role of pain behaviors in the modulation of martial conflict in chronic pain couples. Pain 1996;65:227-33.

7. Cano A, Williams ACdeC. Social interaction in pain: Reinforcing pain behaviors or building intimacy? Pain 2010;149:9-11.

8. Craig KD. The social communication model of pain. Can Psychol 2009;50:22-32.

9. Hoffman DE, Tarzian AJ. The girl who cried pain: A bias against women in the treatment of pain. J Law Med Ethics 2001;29:13-27.

10. Hadjistavropoulos HD, Ross MA, von Baeyer CL. Are physicians' ratings of pain affected by patients' physical attractiveness? Soc Sci Med 1990;31:69-72.

11. Hadjistavropoulos T, Craig KD. A theoretical framework for understanding self-report and observational measures of pain: A communications model. Behav Res Ther 2002;40:551-70.

12. Sullivan MJL, Martel MO, Tripp DA, Savard A, Crombez G. Catastrophic thinking and heightened perception of pain in others. Pain 2006;123:37-44.

13. Sullivan MJL, Martel MO, Tripp D, Savard A, Crombez G. The relation between catastrophizing and the communication of pain experience. Pain 2006;122:282-8.

14. Sullivan MJL, Bishop SR, Pivik J. The pain catastrophizing scale: Development and validation. Psychol Assess 1995;7:524-32.

15. Bowlby J. Attachment and Loss. London: Penguin Books, 1969.

16. Bartholomew K, Shaver PR. Methods of assessing adult attachment: Do they converge? In: Simpson JA, Rholes WS, eds. Attachment Theory and Close Relationships. New York: Guilford Press, 1998:25-45.

17. Bartholomew K, Horowitz LM. Attachment styles among young adults: A test of a four-category model. J Pers Soc Psychol 1991;61:226-44.

18. Fraley RC, Waller NG. Adult attachment patterns: A test of the typological model. In: Simpson JA, Rholes WS, eds. Attachment Theory and Close Relationships. New York: Guilford Press, 1998:77-114.

19. Roisman GI, Fraley RC, Belsky J. A taxometric study of the Adult Attachment Interview. Dev Psychol 2007;43:675-86.

20. Griffin DW, Bartholomew K. The metaphysics of measurement: The case of adult attachment. In: Bartholomew K, Perlman D, eds. Advances in Personal Relationships, Volume 5: Attachment Processes in Adulthood. London, UK: Jessica Kingsley Publishers Ltd, 1994:17-52.

21. Fraley RC, Niedenthal PM, Marks M, Brumbaugh C, Vicary A. Adult attachment and the perception of emotional expressions: Probing the hyperactivating strategies underlying anxious attachment. J Pers 2006;74:1163-90.

22. Collins NL. Working models of attachment: Implications for explanation, emotion, and behavior. J Pers Soc Psychol 1996;71:810-32.
23. Kunce LJ, Shaver PR. An attachment-theoretical approach to caregiving in romantic relationships. In: Bartholomew $\mathrm{K}$, Perlman D, Bartholomew K, Perlman D, eds. Attachment Processes in Adulthood. London, UK: Jessica Kingsley Publishers, 1994:205-37.

24. Feeney BC, Collins NL. Predictors of caregiving in adult intimate relationships: An attachment theoretical perspective. J Pers Soc Psychol 2001;80:972-94.

25. Simpson JA, Rholes WS, Nelligan JS. Support seeking and support giving within couples in an anxiety-provoking situation: The role of attachment styles. J Pers Soc Psychol 1992;62:434-46.

26. Porter LS, Davis D, Keefe FJ. Attachment and pain: Recent findings and future directions. Pain 2007;128:195-8.

27. McWilliams LA, Asmundson GJG. The relationship of adult attachment dimensions to pain-related fear, hypervigilance, and catastrophizing. Pain 2007;127:27-34.

28. Meredith PJ, Strong J, Feeney JA. The relationship of adult attachment to emotion, catastrophizing, control, threshold and tolerance, in experimentally-induced pain. Pain 2006;120:44-52.

29. Mikulincer M, Shaver PR. Attachment theory and emotions in close relationships: Exploring the attachment-related dynamics of emotional reactions to relational events. Pers Relatsh 2005; 12:149-68.

30. Brennan KA, Clark CL, Shaver PR. Self-report measurement of adult attachment: An integrative overview. In: Simpson JA, Rholes WS, Simpson JA, Rholes WS, eds. Attachment Theory and Close Relationships. New York: Guilford Press, 1998:46-76.

31. Nayak S, Shiflett SC, Eshun S, Levine FM. Culture and gender effects in pain beliefs and the prediction of pain tolerance. J Cross Cult 2000;34:135-51.

32. Aiken LS, West SG. Multiple Regression: Testing and Interpreting Interactions. Thousand Oaks: Sage Publications Inc, 1991.

33. Belsey DA, Kuh E, Welsch RE. Regression Diagnostics: Identifying Influential Data and Sources of Collinearity. New York: Wiley, 1980.

34. Hobara M. Beliefs about appropriate pain behavior: Cross-cultural and sex differences between Japanese and Euro-Americans. Eur J Pain 2005;9:389-93.

35. Brumbaugh CC, Fraley RC. Transference of attachment patterns: How important relationships influence feelings toward novel people. Pers Relatsh 2007;14:513-30.

36. Collins NL, Feeney BC. Working models of attachment shape perceptions of social support: Evidence from experimental and observational studies. J Pers Soc Psychol 2004;87:363-83.

37. Horowitz LM, Rosenberg SE, Bartholomew K. Interpersonal problems, attachment styles, and outcome in brief dynamic psychotherapy. J Consult Clin Psychol 1993;61:549-60.

38. McWilliams LA, Saldanha KM, Dick B, Watt M. Development and psychometric evaluation of a new measure of pain-related support preferences: The Pain Response Preference Questionnaire. Pain Res Manage 2009;14:461-9.

39. Holtzman S, DeLongis A. One day at a time: The impact of daily satisfaction with spouse responses on pain, negative affect and catastrophizing among individuals with rheumatoid arthritis. Pain 2007;131:202-13.

40. Lundquist LM, Higgins NC, Prkachin KM. Accurate pain detection is not enough: Contextual and attributional style as biasing factors in patient evaluations and treatment choice. J Appl Biobehav Res 2002; 7:114-32. 


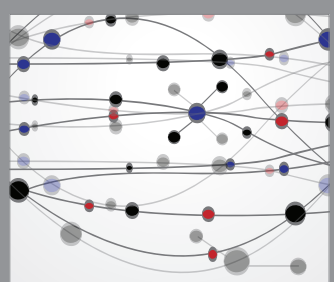

The Scientific World Journal
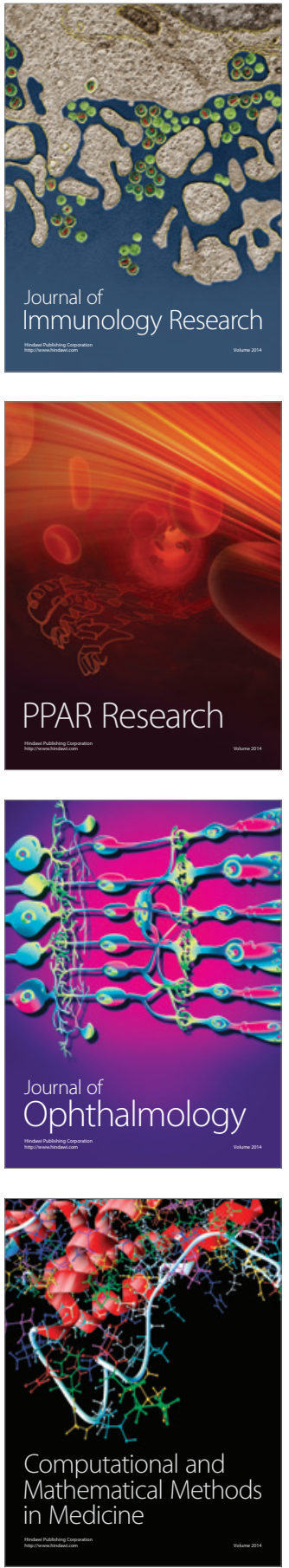

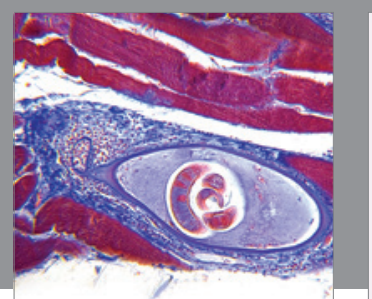

Gastroenterology Research and Practice

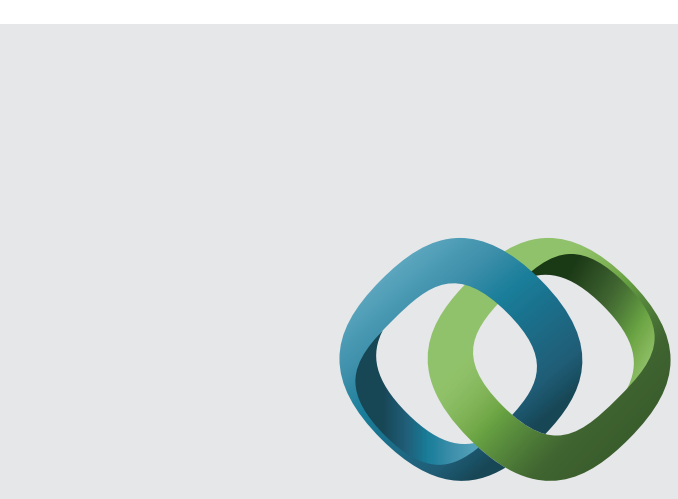

\section{Hindawi}

Submit your manuscripts at

http://www.hindawi.com
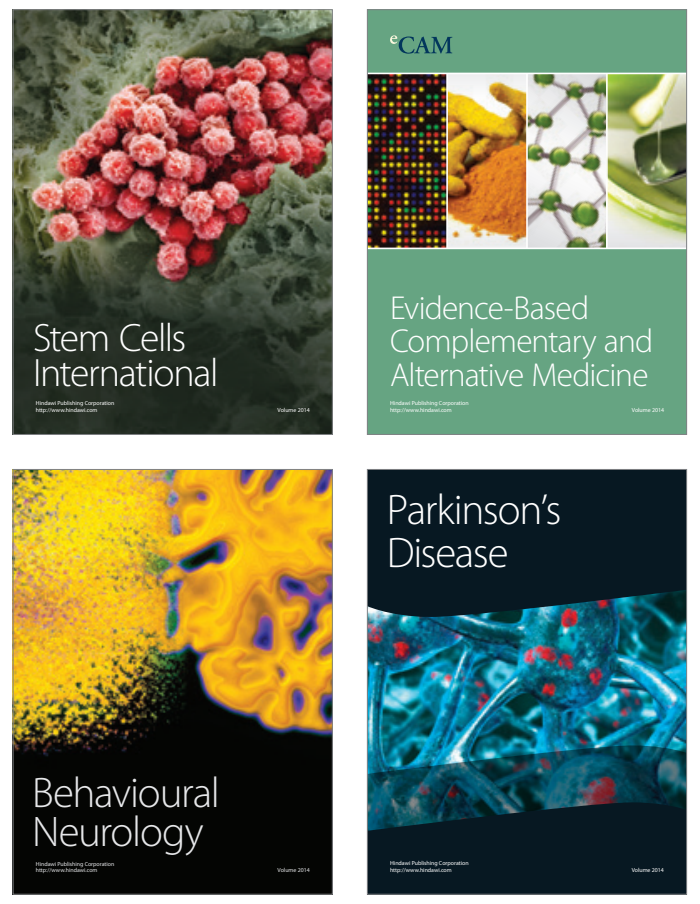
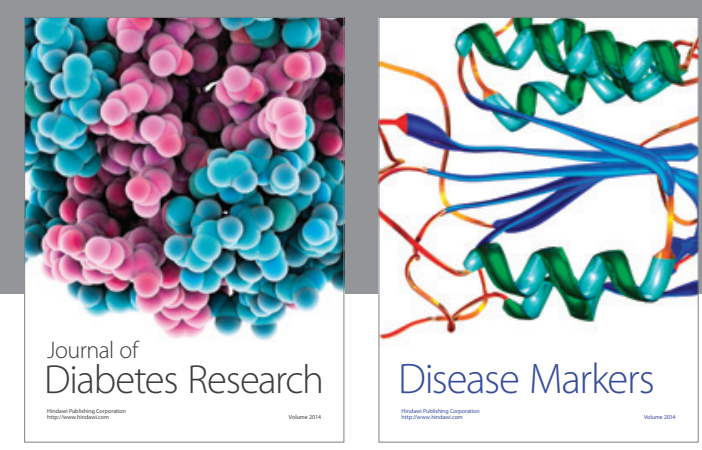

Disease Markers
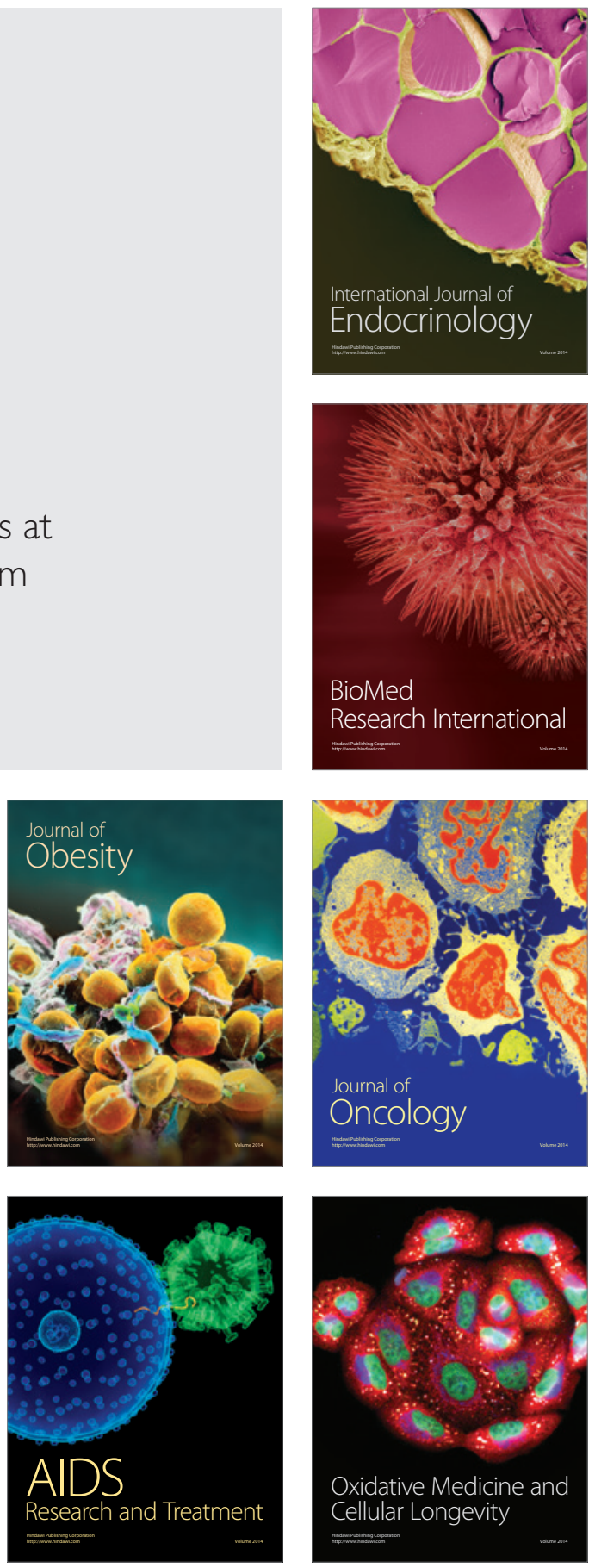